\title{
VARIATION IN THE AGRONOMIC CHARACTERS OF MICROSPORE-DERIVED PLANTS OF HORDEUM VULGARE CV. SABARLIS
}

\author{
W. POWELL, A. M. HAYTER, W. WOOD,* J. M. DUNWELL AND B. HUANG† \\ Scottish Crop Research Institute, Pentlandfield, Roslin*; John Innes Institute, \\ Colney Lane, Norwicht
}

Received 15.vi.83

\section{SUMMARY}

Seventy-four spontaneously doubled microspore-derived (M) lines of Hordeum vulgare $\mathrm{cv}$. Sabarlis were grown in the field and their agronomic performance compared with that of 16 selfed seed-derived (S) lines. It was found that two of the characters scored, namely mildew susceptibility, and growth habit did not show any differences between $S$ and $M$ lines. In contrast, the other seven characters, days to awn emergence, plant height, neck length, number of fertile tillers, number of grains on the main tiller, grain yield on the main tiller, and thousand grain weight, all showed significant differences between the $M$ lines and not between the $S$ lines. Overall, the $M$ populations tended to be later to awn emergence, and to be taller with longer necks and fewer tillers than the $S$ population.

Possible explanations for this variation are discussed in relation to other examples of "somaclonal variation" described amongst plants regenerated from cultured cells.

\section{INTRODUCTION}

Microspore-derived plants may now be produced on a relatively large scale in a range of species which include many agronomic crops. It has been known for some time that such plants may possess either the haploid chromosome complement or be polyploid in nature (Sunderland and Dunwell, 1977). It is important in the latter cases to distinguish between non-haploids which are homozygous and those which are heterozygous. There is now evidence that even the apparently homozygous progenies from inbred varieties may show some genetic variation. Most of the evidence of this variation has come from studies of Nicotiana. It was first reported by Kadotani and Kubo (1969) that the flower and leaf morphology of a doubled haploid line of the flue cured tobacco variety Bright Yellow differed from the parental diploid. Such studies have since been extended by Oinuma and Yoshida (1974), Burk and Matzinger (1976), Arcia et al., (1978), Schlitz et al., (1980), and most recently by De Paepe et al., (1981, 1982), Javier (1981) and Brown and Wernsman (1982). This latest study showed that microspore-derived dihaploid lines from highly inbred cultivars of flue cured tobacco are lower yielding and agronomically inferior to selfed progenies of the parental plants. It must be stated that this conclusion is at variance with evidence from burley tobacco varieties (Deaton et al., 1982).

Similar, though less extensive, studies have been conducted on certain cereal species. The main evidence available is from rice, which is the cereal most amenable to microspore plant production. It was found first by Oono $(1975,1981)$ and subsequently by Kuo et al., (1980), Dosso-Yovo et al., 
(1980), Schaeffer (1982) and Wakasa (1982) that doubled haploid lines of rice derived from one genotype showed a range of phenotypes. Recently, Bui Dang Ha and Pernes (1982) have reported the recovery of variants from microspore derived plants of pearl millet. In none of these examples is the variation due to any obvious chromosomal abnormality.

A similar amount of evidence is not available for barley. Although polyploid variants have been described (Wilson et al.,1977) recent studies (Friedt and Foroughi-Wehr, 1981, 1983; Foroughi-Wehr et al., 1983) have concentrated on descriptions of progenies from F1 hybrid material and the only account of variation from an inbred cultivar is that of San Noeum and Ahmadi (1982) who compared three microspore-derived doubled haploid lines of the cultivar Berenice with two families derived from cultured ovaries. They found that the ovary-derived doubled haploids were similar to the source material whereas the microspore-derived lines were significantly different from it.

The present study was designed to assess the degree of variation in agronomic characters of a large number of lines derived from cultured microspores of the barley cultivar, Sabarlis.

\section{MATERIALS AND METHODS}

The anther culture lines were derived from the barley cultivar, Sabarlis. Methods of spike collection, pre-treatment and culture were as described by Huang and Sunderland (1982). Spontaneously doubled haploids were produced from the parental material and self pollinated to produce a total of 74 distinct microspore-derived (M) lines. The material was grown in the field at The Murrays Farm, Pathead, East Lothian (Grid Reference NI 413633) in 1982. A sample of plants from each family was tested and found to have an apparently normal karyotype $(2 n=14)$ in their root tips. The same Sarbarlis parental material was allowed to self pollinate and sixteen seed-derived (S) lines were included in the experiment to make a total of 90 families.

The experimental design was a randomised complete block of four replicates. Within each block, each family was represented by a row of 10 plants sown at $50 \mathrm{~mm}$ spacings, with a guard plant of the cultivar Golden Promise sown at the end of every row. Each row was spaced at $225 \mathrm{~mm}$ from its neighbours and each block was made up of 90 rows of experimental material with 5 Golden Promise guard rows at each end. The whole experiment was netted to prevent bird damage.

During the growing season a number of characters was scored on a row basis:

(a) Mildew susceptibility (Erysiphe graminis f.sp. hordei)

(b) Growth habit

(c) Awn emergence, days from the 1st June until awns emerged from the flag sheath on the main tiller.

After harvesting, sheaves were returned to the laboratory and the following measurements made on 5 randomly chosen plants from each row:

(a) Neck length $(\mathrm{cm})$ measured as the distance between the flag leaf auricles and the collar. 
(b) Final plant height $(\mathrm{cm})$

(c) Number of fertile tillers

(d) Number of grains on the main tiller

(e) Grain yield of the main tiller (g)

(f) Thousand grain weight (g) obtained from (c) and (d)

\section{Results}

The data from the experiment were analysed using two-way analysis of variance with 5 observations per cell. Of the characters scored on a row basis, only awn emergence showed significant variation between the (M) lines. Data for mildew susceptibility and growth habit are therefore not presented. An analysis of variance of the awn emergence data plus that from the five characters scored after harvest is given in table 1 . This shows first the significant amount of variation $(P<0.001)$ that exists between replicates of both the $\mathrm{M}$ and $\mathrm{S}$ lines. However, there is no significant variation between the $S$ lines, in contrast to the $\mathrm{M}$ lines which show great variation for all six characters.

The comparisons which have a single degree of freedom are shown in table 2 where the means and ranges of each character are given. The $M$ and $\mathrm{S}$ lines were significantly different for neck length, height and tiller number but not for grain number and thousand grain weight. Although the variation in the $\mathrm{M}$ lines was distributed in both directions around the mean performance of the $S$ lines, the $M$ populations tended to be later to reach awn emergence, to be taller and have longer necks with fewer tillers per plant.

In order to estimate the components of variance ascribable to the main effects and to interactions, the expected mean squares were used. These provide an estimate of the proportion of the total variance $\left(\sigma^{2} T\right)$ which can be ascribed to differences between $M$ and between $S$ lines $\left(\sigma^{2} L\right)$ as opposed to differences within lines. It is of interest in this context that the high percentage variability shown by the $M$ lines for awn emergence and thousand grain weight is in accord with the findings from genetic analyses (Tapsell and Thomas, 1983) which showed these characters to have high heritabilities.

\section{Discussion}

The lines derived from plants regenerated from microspore callus of the cultivar Sabarlis differed from the parental lines in a number of important agronomic characters. The variability displayed by the $(\mathrm{M})$ population for components of yield are of particular interest. Tiller number, grain number and 1000 grain weight all showed significant between-line variability in the (M) populations but not in the (S) populations.

Having described the extent of this variation, there remain a number of further points to be discussed. The first concerns the source of this variation and the second concerns the possibility that some of this variation may be useful for plant breeding purposes. The major study of the first topic has been conducted on tobacco (Javier, 1981; Brown and Wernsman, 1982). Both studies concluded that the variation and yield depression amongst doubled haploid lines derived from microspores of flue-cured 


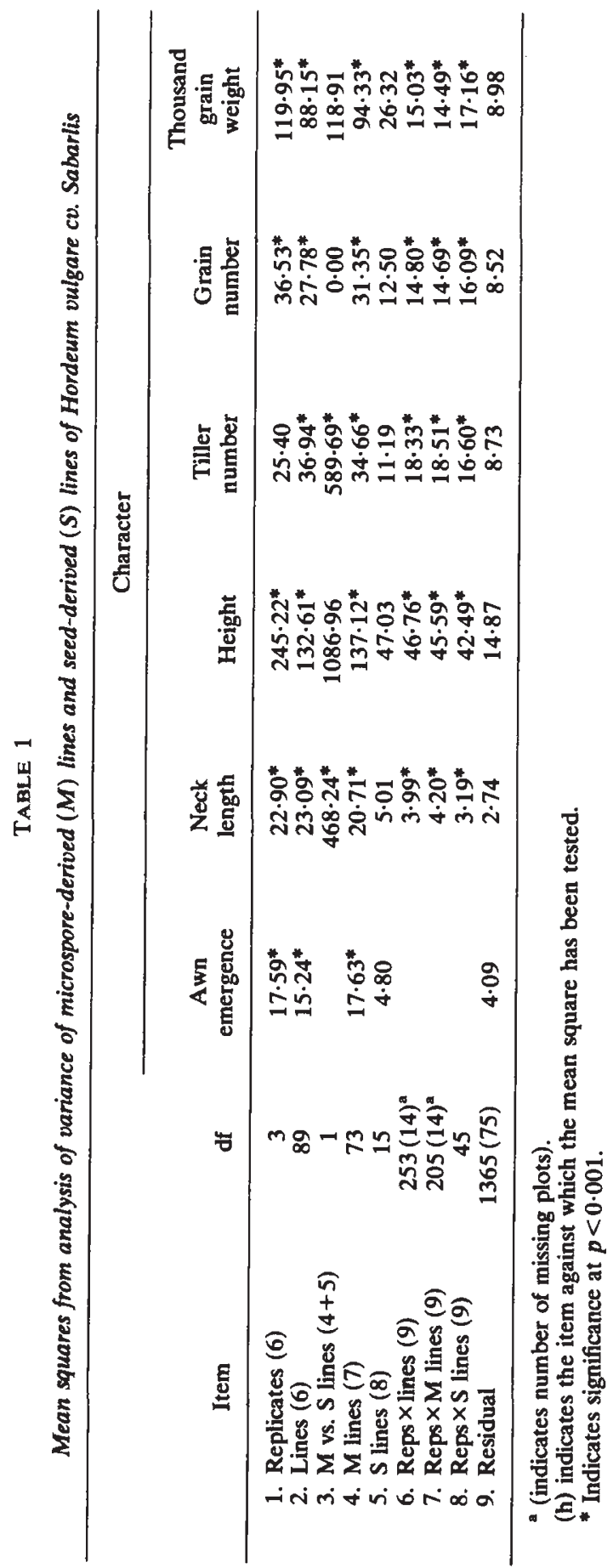


TABLE 2

Means, standard deviations, and ranges of microspore-derived $(M)$ lines and seed derived $(S)$ lines of Hordeum vulgare, $c v$. Sabarlis

\begin{tabular}{|c|c|c|c|c|c|c|}
\hline Character & $\begin{array}{c}\text { Lines } \\
\mathbf{M} \\
\text { mean }\end{array}$ & $\begin{array}{l}\text { Standard } \\
\text { deviation }\end{array}$ & Range & $\underset{\text { mean }}{S}$ & $\begin{array}{l}\text { Standard } \\
\text { deviation }\end{array}$ & Range \\
\hline Awn & $32 \cdot 4$ & 4. & 20.0 & 30.85 & 2 . & 28 . \\
\hline Neck length & 2 & 4 & 0.98 & 1.42 & 2 & .42 \\
\hline Height & $84 \cdot 79$ & $11 \cdot 71$ & $76 \cdot 18-92 \cdot 88$ & $82 \cdot 70$ & $6 \cdot 86$ & $79 \cdot 90-82 \cdot 75$ \\
\hline Tiller number & $8 \cdot 42$ & $5 \cdot 89$ & $3.00-11 \cdot 80$ & 9.93 & $3 \cdot 35$ & $8 \cdot 90-11 \cdot 10$ \\
\hline \multirow{2}{*}{$\begin{array}{l}\text { Grain number } \\
\text { Thousand grain } \\
\text { weight }\end{array}$} & $24 \cdot 76$ & $5 \cdot 60$ & $18 \cdot 34-26 \cdot 40$ & $24 \cdot 76$ & $3 \cdot 54$ & $23 \cdot 90-26 \cdot 20$ \\
\hline & $37 \cdot 59$ & $9 \cdot 71$ & $20 \cdot 00-37 \cdot 00$ & $30 \cdot 85$ & $2 \cdot 19$ & $28 \cdot 15-32 \cdot 41$ \\
\hline
\end{tabular}

TABLE 3

Variances of the means $\left(\sigma^{2} L\right)$ and percentage of the total variance $\left(\sigma^{2} L / \sigma^{2} T \times 100\right)$ ascribable to differences between lines for microspore-derived $(M)$ lines and seedderived $(S)$ lines of Hordeum vulgare cv. Sabarlis

\begin{tabular}{lcccc}
\hline & \multicolumn{3}{c}{ Variance of means } & \multicolumn{3}{c}{ Percentage of total variance } \\
\cline { 2 - 6 } \multicolumn{1}{c}{ Character } & \multicolumn{2}{c}{ Lines } & \multicolumn{3}{c}{ Lines } \\
\hline Awn emergence & M & S & M & S \\
Neck length & 3.39 & 0.18 & 44.37 & 4.17 \\
Height & 0.83 & 0.09 & 20.89 & 3.41 \\
Tiller number & 4.58 & 0.28 & 17.67 & 0.97 \\
Grain number & 0.81 & 0.00 & 7.20 & 0.00 \\
Thousand grain weight & 0.83 & 0.00 & 8.02 & 0.00 \\
& 3.99 & 0.46 & 27.80 & 4.12 \\
\hline
\end{tabular}

tobacco varieties were largely, if not exclusively, nuclear in origin and that the mutations were generally recessive. They rejected the suggestion that variability might have been due to residual heterozygosity or induced by the colchicine used for doubling (Deaton et al., 1982). It must be stressed that all lines in the present study were produced after spontaneous chromosome doubling. Moreover, studies of this type on other species have reached conclusions similar to those from flue-cured varieties of tobacco. Oono (1975) and Wakasa (1982) working with rice concluded that nuclear mutation may occur either at the haploid level, before chromosome doubling, or at the diploid level after chromosome doubling. The related study on three microspore derived lines of barley (San Noeum and Ahmadi, 1981) showed important maternal and reciprocal effects when these lines were intercrossed with each other and with control parental diploids. Data from this latter study may also be used to refute one possible criticism of the present study. It has been suggested that considerable heterozygosity exists in the original varietal material and it is therefore theoretically possible that the variation found is solely due to the unbuffered and therefore unstable nature of the completely homozygous microspore derivatives. However, this argument could not be true in cases where the microsporederived doubled haploids show variation that does not exist amongst egg 
cell derived doubled haploids (San Noeum and Ahmadi, 1982). A second possible explanation which cannot yet be entirely discounted is the possibility that there may be between-line cytological variation which is not visible in a simple mitotic analysis and which may be revealed by a detailed meiotic study. The high level of fertility in the present study, however, would argue against there being any major cytogenetic abnormalities.

Even if mutation is finally confirmed as the explanation for the variation, its nature remains unknown. There have been no convincing demonstrations of the type of mutation process that might be occurring in the microspore or pollen grain, or in their immediate products. Various suggestions have been made concerning possible qualitative or quantitative differences between the DNA of the vegetative cell of the pollen grain from which, at least in tobacco, the pollen plant is produced, and the DNA of the egg cell from which the normal zygote is derived (De Paepe et al., 1981, 1982; Brown and Wernsman, 1982; Dhillon et al., 1983). However, such suggestions remain as speculation.

The final major point to be discussed involves the possible advantageous variation that may be created or fixed by the culture procedure. It should be mentioned that for many crop species, and in particular for cereals, lack of genetic variability is not the limiting factor for their further improvement; the chief constraint is the difficulty of identifying and isolating desired recombinants. Therefore, before the type of variation described in the present study can be regarded as a useful adjunct to conventional breeding methods it would be desirable not only to establish the nature and source of the variation but also to control the degree of variation. If that can be achieved, then the concept of somaclonal variation (Edallo et al., 1981; Larkin and Scowcroft, 1982) may indeed prove to be a valuable one, but only if this type of spontaneous mutation is shown to be different in quantity or quality from induced mutation. There is no a priori reason to suppose that this should be the case.

\section{REFERENCES}

ARCIA, M. A., WERNSMAN, E. A. AND BURK, L. G. 1978. Performance of anther-derived dihaploids and their conventionally inbred parents as lines, in F1 hybrids, and in F2 generations. Crop Sci., 18, 413-418.

BROWN, J. S. AND WERNSMAN, E. A. 1982. Nature of reduced productivity of anther-derived dihaploid lines of flue-cured tobacco. Crop Sci., 22, 1-5.

BUI DANG HA, D. AND PERNES, J. 1982. Androgenesis in pearl millit. I. Analysis of plants obtained from microspore culture. Z. Pflanzenphysiol., 108, 317-327.

BURK, L. G. AND MATZINGER, D. F, 1976. Variation among anther-derived doubled haploids from an inbred line of tobacco. J. Hered., 67, 381-384.

DEATON, W. R., LEGG, P. D. AND COLLINS, G. B. 1982. A comparison of burley tobacco doubled-haploid lines with their source inbred cultivars. Theoret. Appl. Genet., 62, 69-74.

DE PAEPE, R., BLETON, D. AND GNANGBE, F. 1981. Basis and extent of genetic variability among doubled haploid plants obtained by pollen culture in Nicotiana sylvestris. Theoret. Appl. Genet., 59, 177-184.

DE PAEPE, R., PRAT, D. AND HUGUET, T. 1982. Heritable nuclear DNA changes in doubled haploid plants obtained by pollen culture of Nicotiana sylvestris. Plant Sci. Letts., 28, 11-28.

DHILLON, S. S., WERNSMAN, E. A. AND MIKSCHE, J. P. 1983. Evaluation of nuclear DNA content and heterochromatin changes in anther-derived dihaploids of tobacco (Nicotiana tabacum) cv. Coker 139. Can. J. Genet. Cytol, 25, 169-173.

DOSSOU-YOVO, S., PRIOUL, J.-L. AND DEMARLY, Y. 1982. Croissance et photosynthèse comparées de phenovariants de riz.-Effet de l'ombrage. Agronomie, 2, 493-502. 
EDAllo, S., ZUCCHINALI, C., PERENZIN, M. AND SAlAMINI, F. 1981. Chromosomal variation and frequency of spontaneous mutation associated with in vitro culture and plant regeneration in maize. Maydica, 26, 39-56.

FOROUGHI-WEHR, B., FRIEDT, W. AND WENZEL, G. 1983. Field experiments with anther derived lines of barley (Hordeum vulgare) and rye (Secale cereale). In Sen, S. K. and Giles, K. L. (eds.) Plant Cell Culture in Crop Improvement, Plenum Press, New York, pp. $475-483$.

FRIEDT, W. AND FOROUGHI-WEHR, B. 1981. Anther culture of barley (Hordeum vulgare L.): plant regeneration and agronomic performance of homozygous diploid progenies. In Barley Genetics IV. Proceedings of the Fourth Barley Genetics Symposium, Edinburgh, 1981, 690-698.

FRIEDT, W. AND FOROUGHI-WEHR, B. 1983. Field performance of androgenetic doubled haploid spring barley from F1 hybrids. Z. Pflanzenzuchtg., 90, 177-184.

HUANG, B. AND SUNDERLAND, N. 1982. Temperature-stress pre-treatment in barley anther culture. Ann. Bot., 49, 77-88.

JAVIER, E. L. 1981. Variability among nonconventionally derived diploid lines of Nicotiana tabacum L. Ph.D. Thesis, North Carolina State Univ., Raleigh, U.S.A.

KADOTANI, N. AND KUBO, T. 1969. Studies on the haploid method of plant breeding by pollen culture (1). Diploidisation of tobacco haploid by root culture and progeny test of diploid plant derived from pith culture. Jap. J. Breed., 19, Suppl. 2, 125-126.

KUO, Y.-C., LIN, M.-H. AND HSIEH, S.-C. 1980. A preliminary observation on field performance of doubled-haploid rice through anther culture. J. Agr. Res., China 90, 131-136.

LARKIN, P. J. AND SCOWCROFT, W. R. 1983. Somaclonal variation and crop improvement. In: Genetic Engineering of Plants: An Agricultural Perspective. Eds. T. Kosuge, C. P. Meredith and A. Hollaender. Plenum Press, New York, pp. 289-314.

OINUMA, T. AND YOSHIDA, T. 1974. Genetic variation among doubled haploid lines of burley tobacco varieties. Jap. J. Breed., 24, 211-216.

OONO, K. 1975. Production of haploid plants of rice (Oryza sativa) by anther culture and their use for breeding. Bull. Nat. Inst. Agr. Sci. D., 26, 139-222.

OONO, K. 1981. In vitro methods applied to rice. In Thorpe, T. A. (ed.) Plant Tissue Culture Methods and Applications in Agriculture, Academic Press, New York, pp. 273-296.

SAN NOEUM, L. H. AND AHMADSI, N. 1982. Variability of doubled haploids from in vitro androgenesis and gynogenesis in Hordeum vulgare L. In Earle, E. D. and Demarly, Y. (eds.), Variability in Plants Regenerated from Tissue Culture, Praeger Press, New York, pp. 273-283.

SCHAEFFER, G. W. 1982. Recovery of heritable variability in anther-derived doubled-haploid rice. Crop. Sci., 22, 1160-1164.

SCHLITZ, P., COUSSiRAT, J. C., CAZAMAJOuR, F., Hitier, G., Albo, J. P. AND DELON, R. 1980. Modifications induites chez $N$. tabacum après doublement du stock chromosomique de types haploides obtenus par culture "in vitro" d'antheres. Ann. Tabac., 16, 5-12.

SUNDERLAND, N. AND DUNWELl, J. M. 1977. Anther and pollen culture. In Street, H. E. (ed.) Plant Tissue and Cell Culture, Blackwell, Oxford, pp. 223-265.

TAPSELL, C. R. AND THOMAS, W. T. B. 1983. Cross prediction studies on spring barley. 2. Estimation of genetical and environmental control of yield and its component characters. Theoret. Appl. Genet., 64, 353-358.

WAKASA, K. 1982. Application of tissue culture to plant breeding-Method improvement and mutant production. Bull. Nat. Inst. Agr. Sci., D 33, 121-200.

WILSON, H. M., FOROUGHI-WEHR, B. AND MIX, G. 1977. Haploids in Hordeum vulgare through anther culture: potential as starting material for genetic manipulation in vitro. In Sanchez-Monge, E. and Garcia-Olmedo, F. (eds.) Interspecific hybridisation in plant breeding, Universidad Politecnica de Madrid, pp. 243-252. 